\title{
Further Observations on the Transpiration, Stomata, Leaf Water-content, and Wilting of Plants.
}

BY

R. C. KNIGHT.

(From the Department of Plant Physiology and Pathology, Imperial College of Science and Technology, London.)

With three Figures in the Text.

$7 \mathrm{HE}$ results of investigations on the transpiration stream and the water-

1 supply of plants have directed attention to the phenomenon of wilting and to its relation to environmental conditions of soil and atmosphere. The essential turgidity of the plant is maintained by virtue of the capacity of the tissues to maintain within them a sufficiency of water. The turgor equilibrium in the cell system is not a simple one. It is complicated by the fact that it is not a static balance, but the water is in a state of continual motion, passing from cell to cell with the upward flow of the transpiration stream. Thus, unless the movement of water is closely regulated, so that as the water leaves a cell it is replaced by the absorption of an equivalent quantity, there must result fluctuations in the state of the turgidity of the cell. Inability of the cell to obtain sufficient water to counterbalance the loss by transpiration or translocation results in wilting. It is evident at the outset therefore that the turgidity of the plant is influenced by the factors governing water loss and water absorption, viz. the atmospheric evaporating power and the quantity and rate of translocation of water through the soil and through the plant. Much attention has therefore been focused on the questions of wilting coefficients and available soil moisture. Tentative efforts have also been made to interpret the wilting process in terms of the functions of the plant. Beyond recognition of the fact that wilting involves a decrease in water-content, little progress has been made in the analysis of the phenomenon. Distinction has been drawn between the early stages of the process, 'incipient wilting', and the later stages, known simply as 'wilting'. It is not at all clear how it is possible to determine the line of demarcation between these two stages of the process, and there is, moreover, no evidence that there is any reason for such demarcation. It may be urged that 'wilting' implies the visible collapse of the leaf, whilst 'incipient

[Annals of Botany, Vol. XXXVI. No. CXLIII. July, 1922.] 
wilting' consists merely of a decrease in leaf water-content without visible collapse. Such a criterion, susceptible as it is to personal error, can hardly be admitted as a help to a real analysis of the problem. Consequently, in the present paper, the term 'wilting' simply denotes a decrease in watercontent.

The concept of 'permanent wilting' $h_{:}$: been employed by Shive and Livingston in a study of the wilting phenon ena. A plant is said to be permanently wilted when transference to an atmosphere saturated with water vapour fails to revive it within twenty-four hours. The difficulty and labour of the determination of the permanent wilting-point are self-evident, and have militated against the use of this method. Bakke $(1,2)$ has preferred to adopt changes in the transpiration rate as criteria of the progress of wilting. He used Stahl's cobalt chloride method, as modified by Shreve and Livingston, for determining transpiration rate, and found that as the plant wilts this rate falls steadily to a minimum, which is maintained for a longer or shorter period, depending upon the species. Following this period the transpiration rate rises rapidly to a maximum before the final decrease accompanying the drying out of the plant. Bakke attributes this sudden increase in transpiration rate to the sudden rupture of the water columns in the plant, and the point at which this occurs is considered to be the permanent wilting-point. No evidence has been adduced, however, to show that this point coincides with, or indeed has any relation to the permanent wilting-point as defined by Shive and Livingston. It appears that experimental demonstration of the sudden rupture of the water columns in the plant, postulated by Bakke, would prove difficult. The permanent wilting-point of Shive and Livingston may be defined as the stage during the wilting process at which the process of diminution of cell water-content, hitherto reversible, becomes irreversible. It is of course conceivable that the passage of the wilting process from the reversible to the irreversible stage may be accompanied by some sudden internal change such as that postulated by Bakke, but at present there appears to be no evidence of the occurrence of a sudden and complete rupture of the water columns such as might be responsible for a sudden increase in the rate of transpiration. The presence of air gaps in the water columns at certain seasons of the year is undoubted. Dixon (10) has dealt with this point at some length, and Farmer (11, pp. 245-7) has traced the gradual disappearance of air from the wood in autumn as indicated by the increase of density. This increase was shown to spread gradually from the basal shoots to those situated nearer the apex of the tree. The bubbles of air appear again in the wood during the summer as the result of the tension set up by the evaporation of water from the leaves, but at present there is no experimental evidence known to the present writer to show whether the apr arance of bubbles is a sudden or a gradual process. A priori, one would xpect that the quantity of air 
present in the path of the transpiration stream would gradually increase as the summer advanced. It is true that the root system steadily develops, but not only does the total area of the transpiring surface of the plant steadily increase, but in addition the atmospheric evaporating power also gradually increases and soil moisture diminishes. All these factors would tend to increase the tension on the water columns. The actual wilting process may obviously be res ded as the result of a further extension of this general seasonal tendency of the environment. As the plant passes from a state of turgor to the wilted condition, there is no reason to expect that at any particular stage all the water columns are suddenly ruptured. It is more natural to suppose that the replacement of water by air is a gradual process during wilting, as during the ordinary seasonal changes, the water columns being severed one by one with the increasing tension, until the number remaining unbroken cannot supply the leaves with sufficient water to keep the plant alive. This view is susceptible to experimental test by means of determinations of density changes during wilting, on the lines of Farmer's observations. It is hoped shortly to carry out an investigation of this point.

Having demonstrated the fact that during wilting the plant reaches a stage at which its transpiring power ceases to diminish and suddenly increases, Bakke (2) sought to discover possible explanations other than his theory of the rupture of the water columns. He attempted to establish a correlation between the increase of transpiring power at the 'permanent wilting' stage and the opening of the stomata which Darwin $(7,8)$ and Darwin and Pertz (9) showed to occur on wilting. Darwin's original methods estimate water loss and not stomatal aperture, but the porometer method of Darwin and Pertz was more direct and confirmed the previous results. Lloyd, using his alcohol method, failed to demonstrate the stomatal opening on wilting, but Laidlaw and Knight (16), with the porometer, obtained results ${ }^{1}$ in agreement with those of Darwin and Pertz. Bakke (2) failed to find any appreciable stomatal opening during wilting, but rightly insists that it is important that the question of stomatal influence on transpiration during wilting should be settled.

It may be considered significant that investigators who have demonstrated the occurrence of stomatal opening during wilting have all used the porometer method, indicating that the result obtained might be due to some inherent quality of the method. It has been shown, however (16), that there is no reason to suppose that the method is at fault in this particular case. A study of the limitations of the method has already been made (14), but it is perhaps desirable to mention some remarks of Gray and Peirce (12) upon the method. They state that : Obviously, stomata within a porometer are shut off from both light and air'. It is true that the

1 For a consideration of the explag thion of this phenomenon, see the paper referred to. 
stomata on that ring-shaped portion of the leaf which is covered by the luting material which attaches the leaf to the apparatus, are shut off from light from below and from external air, but these are not the stomata whose changes are being measured. The porometer does not deal with the stomata covered by the luting material, but with those enclosed by the leafchamber and those on the rest of the leaf, and it is apparently the stomata enclosed by the leaf-chamber which are referred to as being shut off from both light and air. With a clear glass leaf-chamber it is true that some of the reflected light from below is prevented from reaching the leaf, but the diffuse light transmitted through the leaf is unaffected. Further, in a porometer experiment, the stomata, far from being shut off from air, are given freer access to it, in that air passes through the leaf, under the influence of the suction applied, far more rapidly than it would normally do by diffusion. There are, however, grounds for an objection to the porometer method which has not yet been urged. Neger (18) has distinguished between two definite types of leaves. In one type the intercellular spaces are in free communication throughout the leaf and in the other type this intrafoliar communication is interrupted, the system of spaces being divided into more or less numerous units. The former type of leaf Neger calls homobaric and the latter heterobaric. Plainly it would be theoretically possible to attach a leaf-chamber to a heterobaric leaf in such a manner that it would be impossible to draw any air through at all, even though the stomata were wide open. It is evident that in comparing stomata of different plants by the porometer method, it is necessary to consider the condition of the intercellular spaces, a precaution which has already been advocated by the writer (14).

As the result of his experiences with the determinations of stomatal behaviour during wilting (16), the present writer felt convinced that the rise of transpiring power which Bakke found to accompany permanent wilting, could not possibly be associated with the stomatal opening first demonstrated by Darwin's experiments. At the outset the time factor appears to preclude the possibility of any such correlation. Thus, the rise of transspiring power referred to by Bakke is considered to be closely associated with the point at which the wilting process becomes irreversible. This point was reached in practice some days after the transpiration rate had begun to fall as the result of insufficient supply of water to the leaves. On the other hand, Darwin and Pertz, and Laidlaw and Knight, have given the periods which elapse, under different conditions, between the cessation of the supply of water to the leaves and the attainment of the maximum stomatal aperture consequent upon wilting. The longest period recorded by Darwin and Pertz is about 90 minutes, whilst the periods quoted by Laidlaw and Knight varied from 9 to 35 minutes. It is recognized, of course, that comparison of mere time intervals in a matter of 
physiological correlation is inadmissible. The duration of the time interval must be determined by such factors as the rate of transpiration and the amount of water in the plant. It is to be expected that the time interval will be shorter for a single leaf severed at the petiole than for a leaf attached to a severed shoot, the stem of which could supply water to the leaves longer than the petiole alone. No real comparison is permissible which does not take into consideration the physiological state of the plants in the two cases, but in the present case the disparity between the two intervals is significantly large.

Again, the duration of the period of increased transpiring power appears excessively long when compared with the short time occupied by the opening movement of the stomata.

In view of these discrepancies and of the importance of the question whether stomatal opening could be held to account for the increase of transpiring power accompanying permanent wilting, the writer felt that further experiments were desirable in order to obtain more complete information with regard to the significance of the wilting process. The trend of the work has already been indicated in the writer's summary of transpiration work (15).

The first investigation undertaken was the determination of the change of transpiration rate accompanying the stomatal opening caused by wilting. Darwin $(7,8)$ in effect determined transpiration rate changes during wilting, and Darwin and Pertz determined stomatal changes, but there has been until now no attempt made to determine the two simultaneously for the same plant. In the present investigations plants were caused to wilt under controlled conditions, and observations were made at short intervals of stomatal aperture, transpiration and evaporation rates, and of environmental conditions such as temperature, relative humidity; and wind velocity. Since the whole wilting period during which observations were made was usually of less than two hours' duration, and since very frequent observations were necessary, the technical details of the experiment were not simple, and therefore merit some description.

Detached shoots, set up in potometers, were used in this work, the usual precautions being observed in severing the shoots from the plants. Potometers were used in preference to potted plants in order that observations could be made on the rate of water absorption by the stem as well as on the rate of water loss. In this way it was possible to detect any changes in the water-content of the plant during the preliminary period before the water-supply to the stem was intentionally cut off. The potometers were placed in the air flue previously described (3), by means of which the movement of the air passing over the plant could be maintained at a constant velocity. Throughout the experiments the velocity of the air stream has been seven metres per minute. Owing to the short duration of the experi- 
ment it was found possible to maintain the temperature constant within reasonable limits, but, as the humidity was variable, determinations were made of the evaporating power of the air by means of a form of paper atmometer which has been found satisfactory for the evaporation rates normally encountered in south-east England. It consists (see Fig. I) of a circular piece of filter-paper (A), to the centre of which is attached, with sealing-wax or shellac, a small glass cup in the form of a thistle funnel (C), such as is used in porometer work. The filter-paper is supported at its edge by a wire frame (B) which is kept in position by wire stays fixed to the glass cup. The cup and its stem are filled with water and the stem is passed through the rubber stopper of a bottle which acts as a water reservoir and at the same time supports the cup and the paper. As water evaporates from the paper, which must be completely wetted at first, it is replaced from the reservoir, and it is found that no drying out occurs at the

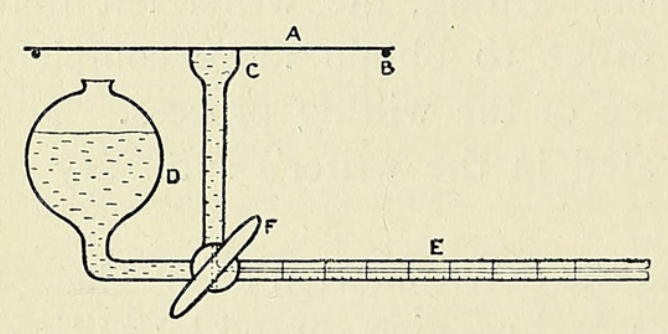

FIG. I. Type of paper atmometer used in transpiration experiments. A. Filter-paper. B. Supporting wire frame. C. Glass cup. D. Reservoir. E. Graduated capillary tube. E. Three-way tap. edges of the paper if the diameter of the cup is sufficiently large-about $I \frac{1}{2} \mathrm{~cm}$. for a $9 \mathrm{~cm}$. filter-paper. The paper must be of a rather loose texture or the conduction of water through it is too slow, although the use of the soft paper shortens the life of the instrument. Evaporation rates are determined by weighings. The apparatus is distinctly fragile, but easy to construct, and with careful handling one will serve for several experiments. It has the advantage that it is very light, and naturally responds to temperature changes more rapidly than porous cup atmometers. It has proved very convenient for greenhouse work, but out of doors it would probably suffer in heavy rain or high wind. In the present experiments; owing to the short time available for observations, this paper atmometer was adapted for rapid volumetric readings in order to save the time which would be occupied by weighing. The leg of the glass cup was sealed into the side of a horizontal graduated capillary tube (E), with a reservoir (D) and three-way cock (F) attached, so that the apparatus resembled a Ganong potometer, the cup and paper replacing the plant. With this apparatus, readings of the evaporation rate could be made over successive periods, each of two or three minutes' duration. Determinations of transpiration rate of the plant and of absorption from the potometer were made eight or ten times per hour. As a weighing ordinarily takes between one and two minutes, the following procedure was adopted in order to save time. The balance was placed on the roof of the air flue, and the potometer was attached to the balance arm by a thread passing through holes in the top of the flue and the base of the 
balance; on the right-hand pan of the balance were placed weights just insufficient to counterbalance the potometer. The beam was then released and its swing observed. With the loss of water by the plant the weight of the potometer eventually became equal to the weight on the right-hand pan, and the time when this occurred was noted with a stop-watch. From the right-hand pan of the balance were then removed weights totalling about 50 to Ico mg., the actual (most convenient) figure being found by experience. The beam was again set swinging and the time taken to restore the equilibrium by further water loss was recorded. Thus, instead of determining the decrease in weight during a period of known length, the time during which the plant lost a known weight of water was measured, and from this the transpiration rate was calculated. For the short period observations necessary in the present experiments this method was found more suitable than the more usual one of weighing at regular intervals. Stomatal changes were recorded automatically by the use of a modification of the recording porometer previously described (16). The modified form of the recorder has been in use for some considerable time, and, owing to its portability and reliability, it is deemed worthy of detailed description here. Air is drawn from the porometer cup through a Mariotte bottle aspirator (A) (Fig. 2) in the usual manner, a constant pressure difference being maintained. In the bottom of the aspirator is a shallow layer of mercury (B), the surface of which just touches the end of the tube (C), from which the bubbles of air emerge into the aspirator. Down the centre of this bubble

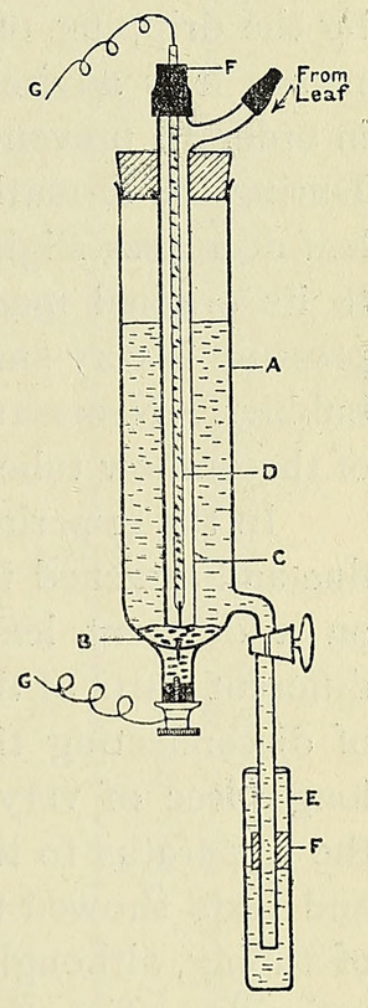

FIG. 2.

Recording porometer. delivery tube passes a mercury platinum electrode (I), the platinum point of which just fails to make contact with the surface of the mercury in the aspirator. Leads (G) from this mercury layer and from the electrode above it connect the two in series with a battery and a magnetic pen marking on the paper on a time-drum rotated by clockwork. The air enters the bubble delivery tube and passes down the annulus between it and the electrode, eventually bubbling up through the water in the aspirator. As a bubble is formed it depresses the mercury surface immediately below it. On the release of the bubble, the mercury, before coming to rest again, oscillates slightly, and in doing so makes contact momentarily with the platinum point of the electrode, thus closing the electric circuit through the battery and the pen. The pen is deflected and makes a record on the drum which indicates the release of a bubble. Thus the passage of every bubble is recorded, and D d 2 
from the frequency of the bubbles can be calculated the rate at which air is being drawn through the stomata. This gives a relative measure of the size of the stomatal aperture. The success of the method depends, of course, on the equality in size of the bubbles. It is found that within reasonable limits these are of the same size as long as the apparatus remains undisturbed, although the depth of the water in the aspirator certainly does slightly influence the size. The variation in the bubble size due to this cause is very small and is also gradual, and is not a serious drawback. The regularity of the bubbles may, however, be considerably interfered with by the dripping of water from the end of the outflow tube, and for this reason it is advisable that this tube should dip into an overflow vessel (E), in order to prevent the periodical jerks on the bubble as the drops fall. During the formation of a bubble the pull on the air passing through the leaf decreases slightly as the mercury surface is depressed, returning again to its original magnitude on the release of the bubble. This change of pressure is very small, and of course the cycle of change is identical for all bubbles. Necessary adjustments of the central electrode and of the height of the outflow tube may be made by means of rubber sleeves (F).

In the experiments under consideration the recorder was placed in the flue and attached by means of T-pieces to two or three leaf-chambers, each on a different leaf. Thus an average reading of stomatal aperture on different parts of the plant was obtained. In order to avoid the necessity of disconnecting the recorder for every weighing to be made, a two feet long piece of very flexible small-bore rubber tubing was used to connect the apparatus to the leaf-chambers. This was allowed to hang in a loop, and tests showed that with a balance sensitive to about $5 \mathrm{mg}$. this length of tubing, although somewhat damping the oscillation of the beam, did not seriously affect the accuracy of the weighings. After setting up the potometers and the recording apparatus, observations were made at short intervals of temperature, relative humidity, loss of weight of the potometer, absorption of water by the plant, and rate of evaporation from the atmometer. The record of stomatal aperture was taken continuously throughout the experiment. After a period of about an hour, during which about ten sets of observations were made, it was possible by comparison of transpiration and water absorption figures to determine whether the water-content of the plant was decreasing under the conditions of the experiment. If no decrease in water-content could be demonstrated, it was assumed that the records of the preliminary period were representative of the normal progress of the functions of the plant. At this stage the water-content of the plant was experimentally diminished. This was accomplished by closing a stopcock at the base of the potometer, thereby cutting off any further supply of water to the cut end of the stem. Observations were continued as before over a period as long as the results warranted, usually one or two hours. 
Stcmata, Leaf Water-content, and Wilting of Plants. 369

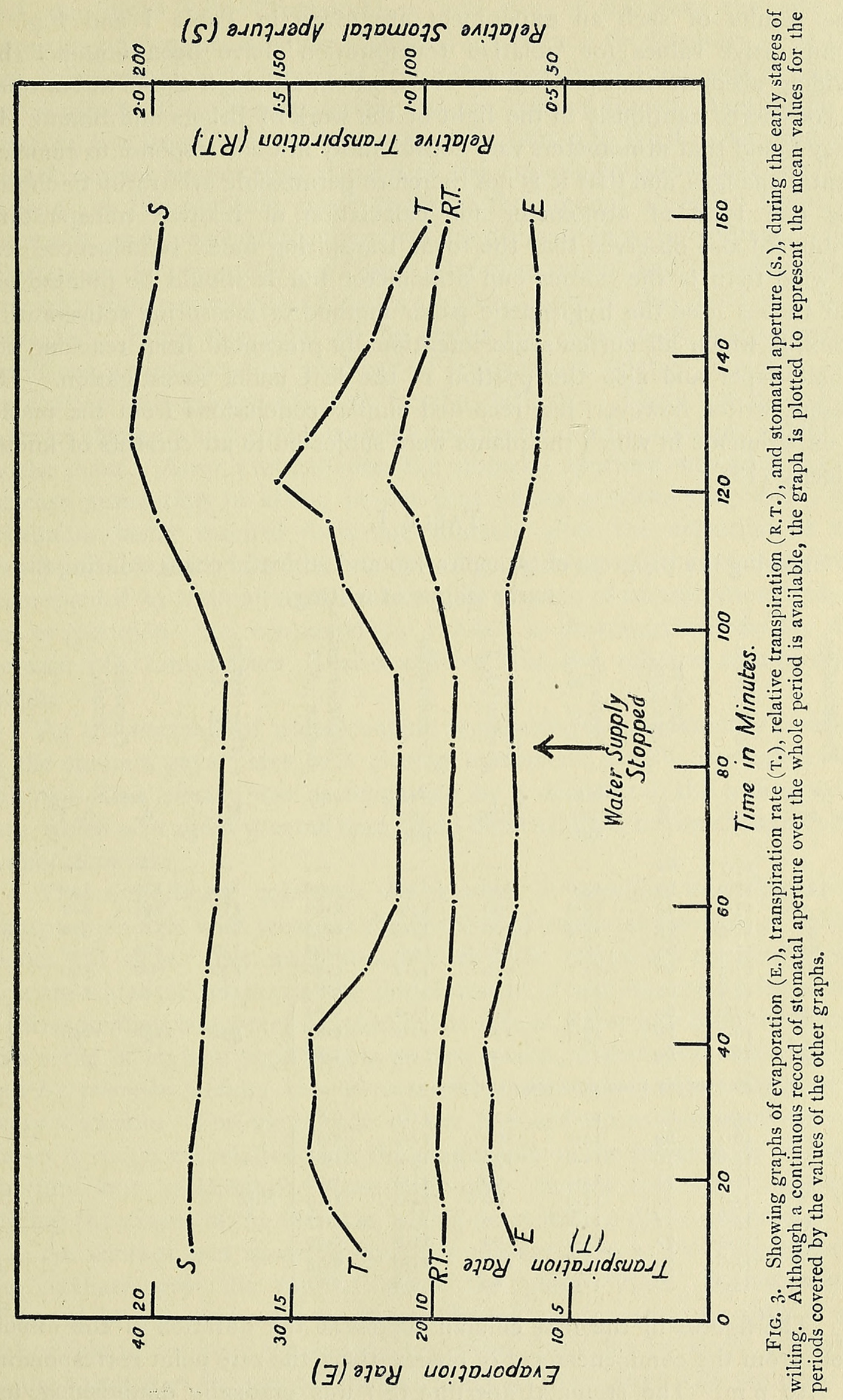


The results of such an experiment are given in Table I and Fig. 3 . Comparative values for 'relative transpiration' have been obtained by dividing absolute transpiration by evaporation, although these values must be considered cautiously in the light of the work of Briggs and Shantz (4). They found that atmometers vary considerably in their response to environmental changes, and that it is not therefore permissible arbitrarily to choose any one type of atmometer for calculation of relative transpiration. Cribbs (6) also observes that the foliar transpiring index is influenced less by wind than is the porous cup atmometer, but it should be pointed out that Cribbs used the hygrometic paper method of measuring transpiration index, in which air currents are intentionally prevented from reaching the cobalt paper and also the portion of the leaf under investigation. The present writer, however, has recorded similar conclusions from the results of experiments in which the plants were subjected to air currents of known velocity (13).

\section{TABLE I.}

Showing the progress of transpiration and stomatal change during the early stages of wilting.

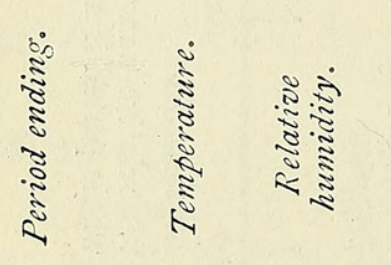

$\begin{array}{cccc}\text { Min. sec. } \quad{ }^{\circ} \mathrm{C} . \quad \% & \begin{array}{c}\mathrm{Mg} . \\ \text { per } \\ \text { min. }\end{array}\end{array}$

$\begin{array}{llll}0 & 8 & 17 \cdot 7 \quad 62\end{array}$

$\begin{array}{llll}9 & 21 & 17.9 & 62\end{array}$

$\begin{array}{rrrr}9 & 21 & 17.9 & 62 \\ 16 & 0 & 17.8 & 63\end{array}$

$23 \quad 4 \mathrm{I} \quad 17 \cdot 5 \quad 65$

$\begin{array}{llll}32 & 16 & 17 \cdot 4 & 65\end{array}$

$\begin{array}{llll}4 \mathrm{I} & 24 & \mathrm{I} 7 \cdot 3 & 66\end{array}$

$\begin{array}{llll}5 \mathrm{I} & \text { I } 4 & \mathbf{1} 7 \cdot 4 & 68\end{array}$

$\begin{array}{llll}6 I & 10 & \text { I } 7.0 & 69\end{array}$

$\begin{array}{llll}72 & I & 16.7 & 70\end{array}$

$82 \quad 5^{8} \quad 16.2$

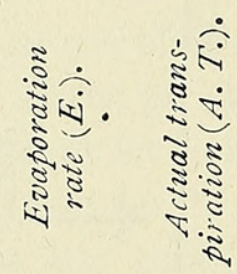

$$
\text { I } \overline{3} \cdot 6
$$

I $5 \cdot 0$

I $5 \cdot 4$

I 5.3

15.7

I 4.6

I $3 \cdot 5$

I $3 \cdot 4$

I $3 \circ 7$

I IO

120

I 30

I 20

I IO

I 20

I 20

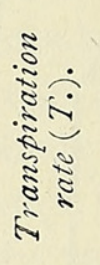
$\begin{array}{cc}\text { Mgm. } & \text { per } \\ & \text { min. }\end{array}$

I30
$90 \quad 13.5$

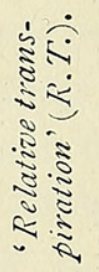

T.
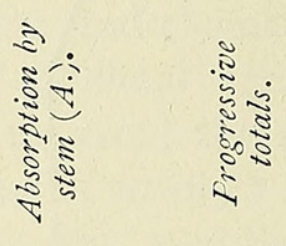

Mg.

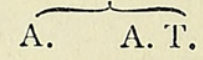

S.

$$
\left.\begin{array}{l}
- \\
0.90 \\
0.90 \\
0.93 \\
0.92 \\
0.90 \\
0.84 \\
0.82 \\
0.83 \\
0.81
\end{array}\right\}
$$

I30
I 10
I00
I 30
I30
I 40
390

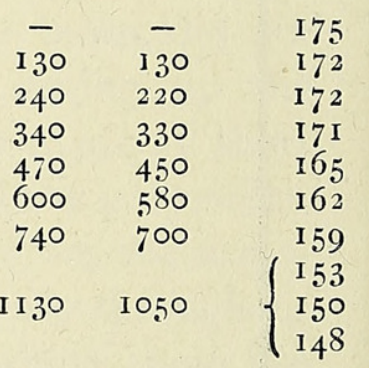

\begin{tabular}{|c|c|c|c|c|c|c|c|c|c|}
\hline 93 & 47 & I 5.9 & 69 & โ.3.8 & I 20 & II $\cdot I$ & 0.80 & \multirow{9}{*}{ Nil. } & I 45 \\
\hline 106 & 12 & $I 6 \cdot I$ & 69 & $I_{4} \cdot I$ & 160 & I 2.9 & 0.92 & & 167 \\
\hline I I 5 & 53 & I 5.8 & 70 & I 2.8 & I 30 & I $3 \cdot 4$ & $\mathrm{I} \cdot{ }^{\circ} 5$ & & I94 \\
\hline $12 \mathrm{I}$ & 47 & ${ }^{1} 5 \cdot 9$ & $7 \mathrm{I}$ & I 2.2 & 90 & $15 \cdot 3$ & $1 \cdot 25$ & & 208 \\
\hline I 28 & 7 & 15.7 & $7 \mathrm{I}$ & II.9 & 90 & $14 \cdot 2$ & I.I 9 & & 212 \\
\hline I 33 & 24 & I 5.8 & 72 & 11.8 & 70 & I $3 \cdot 2$ & I.I 2 & & 210 \\
\hline$I_{4}$ I & $5^{2}$ & ${ }^{1} 5.8$ & $7^{2}$ & I I $\cdot 9$ & 100 & I I 8 & 0.99 & & 204 \\
\hline$I_{5} \mathrm{I}$ & 6 & I $5 \cdot 6$ & $7^{2}$ & II. 8 & 100 & I I .O & 0.93 & & I95 \\
\hline I 59 & 16 & I 5.8 & 72 & I $2 \cdot$ I & 80 & $9 \cdot 8$ & $0.8 \mathrm{I}$ & & I90 \\
\hline
\end{tabular}

Water-supply from potometer stopped.

The figures in the first column represent the duration of the experiment from the commencement of observations, the zero point corresponding to 1.10 p.m. The stomatal aperture (S.) was gradually diminishing, and 
with the slight fall of temperature and rise of humidity the rate of evaporation from the atmometer showed a tendency to decrease. For the first eighty minutes the graph of transpiration rate (T.) followed a course very similar to that of evaporation, and the relative transpiration graph is therefore less irregular than that of transpiration rate itself. All observations taken throughout this portion of the experiment show that the loss of water by transpiration never exceeded the amount absorbed from the potometer, and consequently there was no decrease in water-content. The stopcock on the potometer was closed after observations had been continued for eighty-three minutes, and further water-supply to the shoot was thus prevented. From this point to the end of the experiment environmental conditions, as indicated by readings of temperature, relative humidity, and evaporation rate, showed the same trend as hitherto. There was no sudden external change which could be held responsible for the changes exhibited by the plant. After a few minutes the stomatal aperture showed a sudden increase amounting to about 40 per cent. of its previous magnitude, the maximum being reached forty-one minutes after the cessation of the absorption of water by the stem. The opening of the stomata was accompanied by a simultaneous increase in the rate of transpiration, and, as the evaporation rate continued to exhibit a downward tendency, this increase of transpiration is also reflected in the relative transpiration graph.

As the decrease of water-content proceeded, the preliminary opening of the stomata gave place to a closing movement, usually associated with wilting. This closure was accompanied by a decrease in the transpiration rate, which was again greater than could be attributed to the change in the evaporation rate.

This experiment combines the features of previous experiments on transpiration rate with those on the changes of stomatal aperture of wilting plants. It shows that simultaneously with the temporary opening of the stomata which accompanies the initial stages of wilting, there also occurs a corresponding temporary increase in the rate of water loss from the leaves. In a series of sixteen experiments on two species, Eupatorium adenophorum and Peristrophe speciosa, this increase of transpiration rate has occurred on every occasion. The magnitude of the increase varies considerably, and shows a rough correlation with the magnitude of the increase in stomatal aperture, but undoubtedly there are other factors concerned in determining the extent of the increase. This point will be discussed later.

An attempt was made to correlate the variation in the magnitude of the increase with the rate at which the plant wilted. Unfortunately, different atmometers were used in different experiments, so that it was impossible to compare the evaporation rates from day to day. However, as the velocity of the air motion was constant throughout, the temperature 
of the air during the various experiments gave a rough comparison of the evaporation rates and consequently of the rates of wilting, provided similar plants were used. Table II gives a list of experiments on Eupatorium adenophorum arranged according to the mean temperature of the air surrounding the plants during wilting. The table includes the percentage increase in size of stomata and in transpiration rate, and also the time which elapsed between the cessation of the absorption of water and the attainment of the maximum values of the two functions.

\section{TABLE II.}

Results of experiments on Eupatorium adenophorum, showing the progress of transpiration rate and stomatal change during wilting at different temperatures.

\begin{tabular}{|c|c|c|c|c|c|}
\hline \multirow[t]{2}{*}{$\begin{array}{c}\text { Experiment } \\
\text { No. }\end{array}$} & \multirow{2}{*}{$\begin{array}{l}\text { Mean } \\
\text { temperature } \\
\text { during } \\
\text { wilting. } \\
{ }^{\circ} \mathrm{C} .\end{array}$} & \multicolumn{2}{|c|}{ Percentage increase of: } & \multicolumn{2}{|c|}{$\begin{array}{l}\text { Period elapsing before } \\
\text { attainment of } \\
\text { maximum [minutes] }\end{array}$} \\
\hline & & $\begin{array}{l}\text { Stomatal } \\
\text { aperture. }\end{array}$ & Transpiration. & $\begin{array}{l}\text { Stomatal } \\
\text { aperture. }\end{array}$ & Transp \\
\hline 39 & 13.5 & - & $4 \mathrm{I}$ & - & $6_{4}$ \\
\hline 4I & 14.2 & 25 & 44 & 75 & 75 \\
\hline $3^{8}$ & 14.4 & - & 45 & - & 67 \\
\hline 37 & 14.5 & 574 & 75 & 49 & 43 \\
\hline $3^{6}$ & 15.0 & I 53 & 69 & 37 & \\
\hline $4^{2}$ & 16.0 & 27 & I3 & 30 & 30 \\
\hline 43 & 16.I & 16 & 19 & $5 \mathrm{I}$ & 40 \\
\hline $4^{6}$ & 16.4 & - & 16 & - & $3^{8}$ \\
\hline 35 & I 7.4 & 44 & 37 & $3^{I}$ & 27 \\
\hline $3 I$ & 18.4 & - & $7 \mathrm{I}$ & - & 6 \\
\hline $3^{2}$ & I 8.8 & - & 9 & - & $2 \mathrm{I}$ \\
\hline 33 & 19.0 & - & 39 & - & 18 \\
\hline 29 & - & - & IO & - & I I \\
\hline
\end{tabular}

There is apparently no correlation between the temperature of the air in which wilting occurs (i.e. presumably the velocity of the wilting process) and the magnitude of the accompanying increase in transpiration rate. A similar remark applies to the increase in stomatal aperture. There is, however, a distinct relationship between the temperature during the experiment and the length of the interval between the commencement of wilting and the occurrence of the maximum transpiration rate; this interval may be briefly termed the 'preliminary acceleration period'. Table II shows that the length of this period varies approximately inversely as the temperature. Experiments 39,43 , and 46 are aberrant, but with the data available two of these discrepancies can be accounted for. The relative humidity of the air in the greenhouse in which the experiments were carried out generally varied inversely with the temperature. In Experiment 39, however, the degree of saturation was unusually low for the temperature70 per cent. instead of over 80 per cent. This would, of course, tend to increase the velocity of wilting. Conversely, in Expt. 43 the humidity was 79 per cent. instead of about 70 per cent., which was more usual at $6^{\circ} \mathrm{C}$., 
and in this case the rate of wilting would be correspondingly slower. These circumstances would tend to displace the respective experiments from their position in Table II in the direction of the positions in which they are actually found. The aberration of Expt. 46 remains unaccounted for, but on the whole the series is consistent, and shows the close correlation between the air temperature and the duration of the preliminary acceleration period. Consideration of the stomatal aperture figures in Table II shows an exactly similar correlation existing between the air temperature during wilting and the duration of the preliminary period, with the reservation that Expt. 43 is again aberrant. This discrepancy is amenable to explanation as in the case of the transpiration results. This correlation between air temperature and the rapidity with which maximum stomatal aperture is reached has been observed and recorded in a less complete form by Laidlaw and Knight (16), and it is significant that a similar relationship has been found when studying transpiration rate. There appears to be no doubt that these maxima in the graphs of stomatal aperture and transpiration rate represent a definite stage in the physiological changes accompanying wilting. The more rapid attainment of these maxima which is associated with higher air temperatures is an indication that the plant is wilting more rapidly, and in fact, as Laidlaw and Knight suggested, the duration of the preliminary acceleration period is an indication of the rate at which the plant is wilting.

Another point which may be considered in this connexion is the relation between the preliminary acceleration period of the stomata and that of the transpiration rate. Including the figures in Table II, there are available for comparison nine experiments in which complete records of stomatal aperture and of transpiration rate were obtained. In four of these the maxima of the two graphs appeared simultaneously, in five the maximum of transpiration was reached before that of stomatal aperture, and in none did the stomatal aperture maximum appear first. It must be pointed out that all the recorded figures are averages over periods of varying lengths, and that therefore, whilst an apparent difference between the times of the occurrence of the two maxima indicates a real difference, on the other hand apparent simultaneity does not necessarily mean absolute simultaneity. In the present experiments, had there been an interval of three or four minutes between the appearance of the two maxima, the chances are about even that this interval would have been overlooked. Therefore we may accept the five cases in which the maximum of transpiration rate was reached first, but we are unable to pass judgement on the other four. These five cases provide an instance of the influence of leaf water-content on transpiration rate, irrespective of the effect of stomatal aperture. During the period between the transpiration maximum and the stomatal aperture maximum, the transpiration rate diminishes although the stomatal aperture is increasing. 
This is no doubt due to the fall in leaf water-content and indicates the onset of wilting. This constitutes a special case of the well-known generalization which has now been frequently demonstrated, that in its daily course the transpiration rate reaches a maximum before the atmospheric evaporating power, owing to the check exerted by the decreasing water-content of the leaf.

Having demonstrated by this series of experiments the occurrence of a rise of transpiration rate accompanying the temporary opening of the stomata which occurs during wilting, it is necessary to consider these phenomena in relation to the rise of transpiration rate which Bakke has recorded in association with permanent wilting. It has been pointed out earlier that the interval elapsing before the appearance of the transpiration increase accompanying permanent wilting is very much longer than the interval in the present experiments, but in such a connexion time intervals are useless for comparison unless some criterion of physiological condition is available. It may be urged that in Bakke's experiments the plants were wilting slowly as the result of the gradual failure of the soil water-supply, whereas in the present investigation the velocity of wilting was much greater owing to the sudden complete cessation of the water-supply. This is true, but it is equally true that in the present case, even with the more rapid wilting, the plants never approached the stage of permanent wilting. In order to be sure of this, at the end of each experiment, when transpiration rate was falling and the stomata were closing, the stopcock of the potometer was reopened, allowing water to enter the cut stem again. In every case the shoot recovered its turgidity in the ordinary greenhouse atmosphere without recourse to increased humidity, thus demonstrating that the permanent wilting stage had not been reached. It is evident, then, that the stomatal opening and rise of transpiration rate which have been shown to accompany the initial stages of wilting cannot be associated with the rise of transpiration found by Bakke at the permanent wilting stage. This statement is not intended to rule out the possibility of the recurrence of stomatal opening at a later stage of wilting. In the course of a large number of experiments on the behaviour of stomata during wilting, the writer has never seen any indication of such recurrence, but, although leaves have frequently been allowed to wilt to extreme flaccidity, in none of the experiments has either Bakke's or Shive and Livingston's test for permanent wilting been applied.

An attempt was next made to discover whether the attainment of the maxima of stomatal aperture and transpiration rate represented a stage of the wilting process which could be associated with a definite water-content of the leaf. The relation between the time occupied in reaching these maxima and the air temperature during wilting appeared to indicate that these maxima might be found to occur when a definite quantity of water 
had been lost from the leaves. Experiments were therefore carried out to determine the change of water-content of the leaves during the preliminary acceleration period. The water-content of the cells concerned in transpiration and stomatal change will depend upon the rate at which water passes to these cells from other parts of the plant. Cribbs (6) states that there is evidence that a water deficit may be due to the failure of the watertranslocating system to supply water to the leaves in sufficient quantity to counterbalance the loss by evaporation. It appears that he includes in the term 'translocating system ' the path of the water through the soil and into the roots, as well as the conducting system of the plant. It is self-evident that in a dynamic system such as the plant, the water-content of any particular region must be dependent upon the rate of water translocation. It is evident also that changes in the water-content of the whole plant are not necessarily indications of changes in the water-content of any particular cell. It is therefore inadvisable to use the former and impossible to use the latter for experimental determinations. As a practicable compromise the water-content of a single leaf lamina was adopted as a working basis, and this was determined in conjunction with measurements of stomatal changes, since the latter are easier to obtain and to localize than measurements of transpiration rate. In addition, change of transpiration rate is in the present instance probably almost wholly dependent upon change of stomatal aperture. At the outset, determinations were made of the water-content of leaves of all ages from plants of several species, including Eupatorium adenophorum, which had been used for many of the foregoing experiments. Considerable differences of water-content were found to exist, as indicated in Table III, which gives the figures for all the leaves of one shoot.

\section{TABLE III.}

Water-content of single leaves of Eupatorium adenophorum. I A and I B are two companion leaves from the same node. The same applies to $2 \mathrm{~A}$ and $2 \mathrm{~B}$, \&c.

\section{Leaf No.}

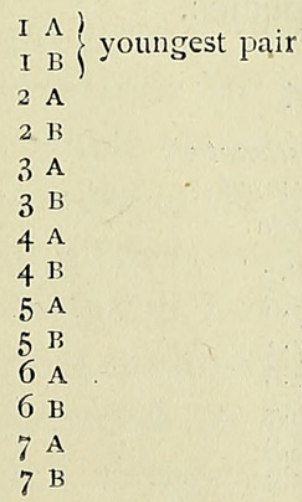

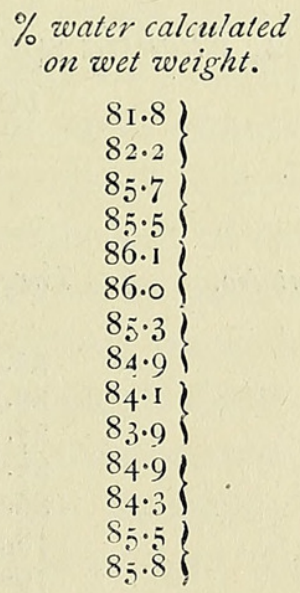

$\%$ water calculated
on wet weight.

$8 \mathrm{I} \cdot 8)$

$82 \cdot 2\}$

$85 \cdot 7$

86.0

$85 \cdot 3\}$

$84 \cdot 9\}$

$85.5\}$ 
There is a great variation in the water-content of different leaves, even if the very young leaves at the tip of the shoot are excluded, but the difference between the two companion leaves from the same node is much smaller, amounting on the average to 0.3 per cent. with a maximum in $6 \mathrm{~A}$ and $6 \mathrm{~B}$ of 0.6 per cent. Large differences in the water-content of different aged leaves were also found in the other species used, which included a Fuchsia species, an Abutilon, ivy-leaved Pelargonium, Morus nigra, and Pleroma macrantha. In view of the results obtained with companion leaves, trials were made with companion leaflets of pinnate leaves of a weeping ash and Juglans regia, and it was found that the figures obtained for these were in even closer agreement than those from companion leaves.

Having obtained information with regard to the water-content of different leaves, the procedure was as follows: A record of stomatal aperture was obtained from a leaf under ordinary conditions, and at a convenient time the leaf was detached from the plant and allowed to wilt, the stomatal record being continued. When this leaf was detached its companion leaf was also detached and its water-content determined. When the stomata of the wilted leaf had ceased their preliminary opening movement and had begun to close, the stomatal record was stopped, and the leaf was removed from the leaf-chamber, weighed, and dried in the usual manner for watercontent determination. The difference between the two values thus obtained represented the change of water-content of the leaf in passing from a condition of turgidity to the stage of wilting marked by the attainment of maximum preliminary stomatal opening. Account must of course be taken of the limits of accuracy imposed by the variation in water-content of companion leaves, which was demonstrated by Table III. The results of a series of these experiments are given in Table IV.

\section{TABLE IV.}

Showing change of water-content of a wilting leaf during the preliminary acceleration period.

1. and 2, Fuchsia species. 6, 7, 8, Eupatorium adenophorum. Iо, I I, Abutilon species.

Water content of leaf.

$\begin{array}{cccc}\text { Experiment No. } & \text { Turgid. } & \begin{array}{c}\text { When stomata } \\ \text { had ceased } \\ \text { to open. }\end{array} & \text { Difference. } \\ \text { I } & 88.9 & 88.7 & -0.2 \\ 2 & 88 . \mathrm{I} & 87.6 & -0.5 \\ 6 & 87.2 & 87.4 & +0.2 \\ 7 & 87.2 & 85.6 & -\mathrm{I} \cdot 6 \\ 8 & 86.8 & 86.7 & -0 . \mathrm{I} \\ 10 & 78.4 & 76.8 & -\mathrm{I} \cdot 6 \\ 11 & 79.9 & 78.8 & -\mathrm{I} \cdot \mathrm{I}\end{array}$


In no case was a decrease in water-content of more than $I \cdot 6$ per cent. found, and it is possible that as much as 0.6 per cent. of this was the original difference between the two companion leaves. The average decrease must be very small, and with the method used it is impossible to determine it with accuracy. The result was rather surprising, since the leaves showing this small decrease in water-content were definitely flaccid. To supplement these results a series of leaves were removed from the plant and allowed to wilt for ten, twenty, and thirty minutes respectively before weighing for watercontent determinations. Observations were made of the appearance of the leaves at the time of weighing and determinations were carried out on companion leaves at the same time, as indicated in Table V.

\begin{tabular}{ccccc} 
& \multicolumn{4}{c}{ TABLE V. } \\
$\begin{array}{c}\text { Water-content } \\
\text { of turgid leaf. }\end{array}$ & $\begin{array}{c}\text { Duration } \\
\text { of wilting } \\
\text { period. }\end{array}$ & $\begin{array}{c}\text { Water-content } \\
\text { at end of } \\
\text { period. }\end{array}$ & $\begin{array}{c}\text { Decrease } \\
\text { in zuater- } \\
\text { content. }\end{array}$ & Afpearance of leaf. \\
84.7 & ro min. & 83.9 & 0.8 & Leaf distinctly flabby. \\
86.0 & 20, & 85.4 & 0.6 & Limp, lustre lost. \\
84.7 & 30, & 83.9 & 0.8 & Limp.
\end{tabular}

These figures demonstrate that extreme flaccidity results from a decrease of approximately I per cent. in leaf water-content. In fact it is easier to detect the early stages of wilting by direct observation than by determination of decrease of water-content. It must be emphasized that the foregoing series of experiments does not actually demonstrate that the stomatal opening which occurs during wilting is brought about by a loss of I per cent. of the water in any particular portion of the leaf-for example, the epidermal cells. The leaf has been treated as a whole in the watercontent determinations, and it is conceivable that, although the mean decrease is only I per cent., the water concerned in wilting, i. e. that contained in the cell sap, may have decreased by a much larger amount. At the same time it is remarkable that a mean decrease of this magnitude should result in such a far-reaching effect as the production of the extreme flaccidity observed.

Interpretation of the phenomenon in terms of single cells results in the rather surprising conclusion that the cell wall is only very slightly distended in the normal turgid state of the cell. The loss of small quantities of water from a cell with an elastic cell wall would simply result in a slight general contraction of the whole structure without any such loss of turgidity as is indicated by the collapse of the leaf. It may of course be possible to distend the cell walls of an already turgid plant by restricting transpiration whilst facilitating water absoption, but the foregoing experiments dealt with typical mesophytes in normal environment, and it is under these conditions that the conclusions are intended to apply. Since visible flaccidity is brought about by such small changes of water-content it is evident that the water 
balance in the plant must be an extremely delicate one. As water is lost by transpiration it must be replaced by translocation of water from the petiole or the stem, and this simultaneous progression may even extend to root absorption, thus permitting the maintenance of almost perfect equilibrium. Otherwise even a small change of transpiration rate induced by slight alteration of the environmental conditions would immediately result in a change in the water-content; a small increase in the wind velocity, for example, would produce visible wilting in a very short time. The leaves of a few plants, e.g. Helianthus, the large-leaved species of Saxifraga, and the root crops, certainly do lose some of their turgidity on very hot days, but it is the exception rather than the rule to find the ordinary mesophytes wilted even on the days of highest atmospheric evaporating power. In the absence, therefore, of any regular occurrence of temporary wilting, it must be concluded that changes of transpiration. rate are accompanied by equal compensating changes of absorption rate. Such close correlation between these two processes is more easily conceivable if part at least of the flow of water through the plant is maintained by the pull, upon continuous tensile water columns, resulting from evaporation and capillarity, than if the elevation of water is effected by directive 'vital' action of leaves or stem. (See Dixon (I0), pp. 24, 25.)

Another aspect of the question of change of water-content is worthy of consideration. It appears paradoxical that whilst a change of I per cent. in leaf water-content may produce such profound results, yet two leaves on the same shoot, apparently quite similar as regards turgidity, may differ in water-content by as much as 4 per cent. This apparent discrepancy may be the result of structural differences-for example, difference of thickness of cell wall. A leaf is a composite structure made up of many different types of tissue, doubtless differing in the percentage of water which they contain. It is evident that a difference in the proportion of the various tissues in two leaves would result in a different percentage water-content of the leaf as a whole.

The variation of leaf water-content during the day and night is rather a different problem and needs special consideration in relation to the results already recorded by other workers. Clark (5) has investigated changes of water-content of leaves of trees, and found that in addition to a seasonal change from a maximum in spring to a minimum at leaf fall there also occurred considerable variations through the day. It was nevertheless found impossible to determine the time of day at which the maximum or minimum water-content was reached, on account of the variation in the results.

The seasonal change of water-content is attributed by Clark to seasonal structural changes similar to those postulated above, but no explanation is advanced to account for the large diurnal changes which. were recorded. The difference in leaf water-content determined at different times of the 
day amounted in one case to more than 20 per cent. $(76.6$ per cent. at Io a.m., 54.7 per cent. at 3 p.m.). Assuming that the dry matter of the leaf remained approximately the same, this means that of the original water in the leaf about 65 per cent. has been lost. This excessive loss of water is very surprising in view of the experiments previously recorded in the present paper, especially as Clark makes no mention of wilting. It is possible, however, that the leaves used in Clark's experiments for water-content determinations at different times of the day were never really comparable at all, but that their respective water-contents differed very considerably at the outset. The present paper has shown that considerable differences may exist even between apparently similar leaves, and Clark has recorded no attempt to determine whether such initial differences existed in the plants which she used. The above interpretation of the enormous differences found by Clark receives additional support from the fact that she found it impossible to associate these variations in water-content with changes of temperature or humidity, or with the changes of evaporating power of the air which occur at different times of the day.

Clark also states as a general conclusion that water-content is independent of transpiration, temperature, and humidity. A study of Clark's results shows that this statement means that water-content varies independently of transpiration, temperature, and humidity. The experimental evidence offered in previous sections of the present paper indicates that, on the contrary, the leaf water-content must remain constant within a very narrow range throughout the day. The flow of water into the leaf appears to be nicely adjusted to counterbalance the loss by transpiration, and the total amount of water in the leaf cells is almost unchanged. Extreme conditions, however, whether caused by excessive transpiration or by lack of soil moisture, might be expected to disturb this delicate equilibrium, at the same time producing flaccidity. In the sense, then, that water-content is almost constant and unaffected by variations of transpiration and external conditions, it may be said to be independent of these changes, but this interpretation of Clark's statements is quite at variance with her results, and is not the one which she accepts.

The work of Livingston and Brown (I 7 ) and of Shreve (19) is relevant to the present work. Investigations carried out by these workers showed that under desert conditions there was a definite diurnal cycle of changes in the water-content of the leaf. A minimum quantity of water was found to be present during the period of high evaporation rate, whilst the maximum water-content was reached at some time during the night when transpiration was low. This would appear to be the natural result of a limited watersupply, in consequence of which the passage of water into the leaves is not sufficiently rapid during the daytime to replace the water lost by transpiration. The influence of these conditions upon transpiration rate has been 
discussed at length elsewhere by various writers and need not be further considered here, but it is necessary to refer to the work of Livingston and Brown, which has a bearing on the phenomena at present under consideration. In their carefully controlled experiments, the difference between the maximum and the minimum leaf water-content was never more than 8 per cent., and in one case, Physalis, only I per cent., with an average for all recorded cases of 5 per cent. This figure, obtained under extreme atmospheric conditions, is widely different from that obtained by Clark, but is probably a much more accurate estimate, as the experiments recorded below tend to show. In view of the very small decrease in leaf water-content which will produce - flaccidity, it is evident that if during the normal daily cycle the leaves of the plants concerned exhibit fluctuations of water-content such as those recorded for the desert habitat, the plants must daily suffer a considerable degree of wilting. This is not the case; on the contrary, the plants under consideration do not wilt to an extent appreciable by observation except in a high wind or as the result of deficient soil moisture. Consequently it was thought desirable to apply the method of Livingston and Brown to the species used in the present work in order to determine the extent of the diurnal changes of leaf water-content. The plants were living in a cool greenhouse or under temperate outdoor conditions, not approximating to those of the desert habitat of the plants of Livingston and Brown. Experiments were carried out with ash, apple, and quince out of doors and with Eupatorium, Peristrophe, and Cycas in a greenhouse. In the case of apple and quince large numbers of leaves were taken and the probable errors were calculated. In dealing with the other species companion leaves or leaflets were compared in the manner indicated in experiments recorded above.

The period of maximum water-content of the leaves used by Livingston and Brown occurred during the morning hours, whilst the minimum was reached during the afternoon. With this result in view determinations were made in the present experiments at two different times of the day; for example, at 8 a.m. when the atmospheric evaporating power was low and the loss by transpiration small, and again at 2 p.m. after a period of rapid transpiration. Table VI gives the result of an experiment using pairs of leaves of Eupatorium adenophorum.

It has previously been emphasized in this paper that in experiments on the water-content of pairs of leaves it must be recognized that the accuracy is limited by the extent of the initial difference between the water-contents of the two companion leaves. The last two columns of the table show that the evaporating power of the air, as determined by a Livingston porous cup atmometer, was at its highest during the morning, between the $8.30 \mathrm{a} . \mathrm{m}$. and the I p.m. water-content determinations, whilst during the period between the I.I 5 p.m. and the $5 . I 5$ p.m. determinations it had fallen to a quarter of its morning value. 
Stomata, Leaf Water-content, and Wilting of Plants. $38 \mathrm{I}$

TABLE VI.

Variation of leaf water-content at different times of the day. Eupatorium adenophorum. Oct. I5, 1919.

\begin{tabular}{|c|c|c|c|c|c|c|c|}
\hline 8.30 a.m. & I $p . m$. & Change. & I. I $5 p . m$. & 5. I 5 p.m. & Change. & $\begin{array}{r}\text { Water } \\
\text { spheri } \\
\text { atmo }\end{array}$ & $\begin{array}{l}\text { ss from } \\
\text { al cup } \\
\text { eter. }\end{array}$ \\
\hline & & & & & & Period. & $\begin{array}{c}\text { Grm. } \\
\text { per hour. }\end{array}$ \\
\hline$\%$ & $\%$ & & $\%$ & $\%$ & & & \\
\hline 80.4 & $79 \cdot \mathrm{I}$ & $-I \cdot 3$ & 82.4 & 82.5 & $+0 . I$ & $8.30\}$ & 0.68 \\
\hline $84 \cdot 2$ & $83 \cdot 3$ & -0.9 & $79 \cdot \mathrm{I}$ & 79.8 & +0.7 & $9 \cdot 30\}$ & 0.08 \\
\hline $84 \cdot 8$ & $83: 8$ & $-I: 0$ & 80.7 & $81 \cdot 7$ & +1.0 & & \\
\hline $84 \cdot I$ & $83 \cdot 2$ & -0.9 & 82.6 & $82 \cdot 2$ & -0.4 & $9 \cdot 30$ & $4 \cdot 7^{2}$ \\
\hline $83 \cdot 4$ & $82 \cdot 7$ & -0.7 & $79 \cdot 7$ & $79 \cdot 9$ & +0.2 & $\mathbf{I 2 . 4 5}$ & \\
\hline 82.0 & $8 \mathrm{I} \cdot 0$ & $-I \cdot O$ & $8 \mathrm{I} \cdot 5$ & $8 \mathrm{I} \cdot 6$ & $+0 . I$ & $\overline{(2.45)}$ & \\
\hline $83 \cdot 5$ & $82 \cdot 7$ & -0.8 & 81.8 & $82 \cdot 7$ & +0.9 & $\left.\begin{array}{r}12.45 \\
2.0\end{array}\right\}$ & $4 \cdot 5^{6}$ \\
\hline $82 \cdot 3$ & $8 r \cdot 9$ & -0.4 & $8 \mathrm{I} \cdot 4$ & $82 \cdot 4$ & $+1 \cdot 0$ & - & \\
\hline 83.0 & $83 \cdot 3$ & +0.3 & $83 \cdot 4$ & $84 \cdot 0$ & +0.9 & $2.0\}$ & \\
\hline 82.0 & $8 \mathrm{I} \cdot 7$ & -0.3 & $8 \mathrm{I} \cdot \mathrm{I}$ & 82.0 & +0.9 & $3.50\}$ & $3 \cdot 09$ \\
\hline 82.5 & $83 \cdot 8$ & $+I \cdot 3$ & $8 \mathrm{I} \cdot 4$ & $8 \mathrm{I} \cdot \mathrm{I}$ & -0.3 & & \\
\hline 81.6 & $8 \mathrm{I} \cdot 7$ & +0.1 & $82 \cdot 5$ & $82 \cdot 9$ & +0.4 & $\left.\begin{array}{l}3 \cdot 5^{\circ} \\
5 \cdot 30\end{array}\right\}$ & I. I I \\
\hline & Mean : & $\left\{\begin{array}{l}-0.5 \\
\pm 0.1\end{array}\right.$ & & Mean : & $\left\{\begin{array}{l}+0.4 \\
\pm 0.1\end{array}\right.$ & & \\
\hline
\end{tabular}

$$
\begin{array}{ll}
\text { Temperature } & \left\{\begin{array}{l}
\text { Max. I } 4.7^{\circ} \mathrm{C} . \text { I } 2.30 \mathrm{p} . \mathrm{m} . \\
\text { Min. } 6.4^{\circ} \mathrm{C} .8 .30 \mathrm{a} . \mathrm{m} .
\end{array}\right. \\
\text { Relative humidity } & \left\{\begin{array}{l}
\text { Max. } 86 \% 5.0 \mathrm{p} . \mathrm{m} . \\
\text { Min. } 57 \% \text { I I.30 a.m. }
\end{array}\right.
\end{array}
$$

Twelve pairs of leaves were dealt with over each period, and between 8.30 a.m. and I p.m. the largest decrease in water-content was I.3 per cent. During this same period one pair of leaves showed an increase of $\mathrm{I} \cdot 3$ per cent., but it is of course probable that this was due to an initial difference in water-content between the two companion leaves. The average decrease of the twelve pairs was 0.5 per cent. with a probable error of O.I per cent. for this average. Three pairs showed an increase in water-content.

The second portion of the experiment covered the afternoon hours when the atmospheric evaporating power, and doubtless also transpiration rate, were rapidly decreasing. Samples taken at I.I 5 p.m. and 5.I5 p.m. showed an average increase in water-content of 0.4 per cent., probable error o. I per cent. Two samples showed a decrease.

Similar experiments have been carried out with a number of species and a résumé of the results is given in Table VII.

Since it was evident that if the water-content of leaves decreased by more than about I per cent. flaccidity must occur, it was expected that no large diurnal changes would be found. Accordingly it was not surprising that in this series of determinations there is no indication of any diurnal change of leaf water-content of a magnitude corresponding to those found by Livingston and Brown, or even approaching those recorded by Clark. 


\section{TABLE VII.}

Summary of experiments on various species to determine changes of water-content through the day.

\begin{tabular}{|c|c|c|c|c|c|c|c|}
\hline \multirow[t]{2}{*}{$\begin{array}{l}\text { Experi- } \\
\text { ment No. }\end{array}$} & \multirow[t]{2}{*}{ Species. } & \multirow[t]{2}{*}{$\begin{array}{l}\text { Time of } \\
\text { first } \\
\text { determina- } \\
\text { tion. }\end{array}$} & \multirow[t]{2}{*}{$\begin{array}{l}\text { Time of } \\
\text { second } \\
\text { determina- } \\
\text { tion. }\end{array}$} & \multicolumn{3}{|c|}{ Change in water-content. } & $\begin{array}{l}\text { No } \\
\text { com } \\
\text { so }\end{array}$ \\
\hline & & & & Average. & Max. & Min. & \\
\hline 83 & $\begin{array}{l}\text { Eupatorium } \\
\text { adenophorum }\end{array}$ & 8.0 a.m. & 2.0 p.m. & -0.25 & -1.8 & +0.7 & 6 \\
\hline 86 & " & 9.0, & $2.0 "$ & -0.6 & $-I \cdot I$ & - & \\
\hline 88 & ", & $8.30 \%$ & $1.0 "$, & -0.5 & $-1 \cdot 3$ & $+\mathrm{I} \cdot 3$ & 12 \\
\hline 88 & ," & I.I 5 p.m. & $5.15 "$ & +0.4 & +1.0 & -0.4 & I 2 \\
\hline $9^{[}$ & $\begin{array}{l}\text { Peristrophe } \\
\text { speciosa }\end{array}$ & 8.30 a.m. & I.I & -0.2 & -0.6 & +0.2 & \\
\hline 93 & Cycas circinalis & 8.45, & I.30 ", & -0.1 & -0.4 & +0.6 & \\
\hline 94 & $\begin{array}{l}\text { Peristrophe } \\
\text { speciosa }\end{array}$ & II.30 ," & $4.15 "$ & +0.1 & - & - & \\
\hline 109 & Quince & 10.0, & $3.30 \quad$, & $+0.4 \pm 0.1$ & +0.6 & +0.1 & \\
\hline IIO & Apple & 3.30 p.m. & 9.30 a.m. & $-0 . I^{-}$ & - & - & \\
\hline 107 & Fraximus & $10.0 \mathrm{a} . \mathrm{m}$. & $3.3 \circ$ p.m. & $-4 \cdot 4^{1}$ & -7.0 & $-3 \cdot 0$ & \\
\hline 108 & , & $9.0 \%$ & 4.0, & $-\mathrm{I} \cdot 4^{1}$ & -2.9 & +1.3 & $2 c$ \\
\hline
\end{tabular}

The writer does not offer any complete explanation of these differences, but suggests that the wide divergence between the habitats of the plants used by Livingston and Brown and of those in the present investigation may account for the difference in behaviour. It is evident that a plant which can suffer a decrease in water-content of 8 per cent. without becoming flaccid is more fitted to flourish in the extreme conditions of a desert habitat than one which loses its turgidity if its leaf water falls from 85 per cent. to 83 per cent.

\section{SUMMARY.}

It has been demonstrated by simultaneous observations that an increase of transpiration rate accompanies the stomatal opening which occurs during the early stages of wilting.

There is no correlation between the temperature of the air in which wilting occurs (i.e. presumably the rate of wilting) and the magnitude of the accompanying increase in transpiration rate or the magnitude of the increase of stomatal aperture.

The time elapsing between the commencement of wilting and the attainment of the maxima of transpiration rate and stomatal aperture is dependent on the rate of wilting. Thus the attainment of these maxima represents definite stages of the wilting process.

These stages are reached very early in the process, before the watercontent of the wilting leaf has decreased more than about I per cent.

1 These shoots were intentionally allowed to wilt between the early and the later determinations to obtain an indication of the magnitude of the water loss corresponding with visible wilting. In the notes of these experiments the leaves in No. 107 are described as 'badly wilted', and those in No. 108 as 'slightly wilted'. 
The commencement of wilting may be inferred from the flaccid condition of the leaves before it is possible to determine experimentally a definite decrease in leaf water-content.

The loss of leaf turgidity following such a small decrease in leaf watercontent indicates that the wall of a normally turgid cell is only slightly distended.

The water-contents of leaves apparently similar may differ by as much as 2 per cent. in Eupatorium adenophorum, and more in other species.

The diurnal change in leaf water-content in south-eastern England amounts to less than 2 per cent., much less than the maximum variation (8 per cent.) previously recorded for desert habitats.

\section{LITERATURE CITED.}

1. Bakke, A. L. : The Index of Foliar Transpiring Power as an Indicator of Permanent Wilting in Plants. Bot. Gaz., I9I5, 1x. 3I4-19.

2. : Determination of Wilting. Bot. Gaz., I918, lxvi. 8I-I I6.

3. Blackman, V. H., and Knight, R. C.: A Method of Controlling the Rate of Air Movement in Transpiration Experiments. Ann. Bot., I9I 7, xxxi. 21 7-20.

4. BRiggs, L. J., and Shantz, H. L. : Comparison of the Hourly Evaporation Rate of Atmometers and Free Water Surfaces with Transpiration Rate of Medicago sativa. Journ. Agr. Res., I9I 7 , ix. 277-92.

5. Clark, Arabel W. : Seasonal Variation in Water Content and in Transpiration of Leaves of Fagus americana, Hamamelis virginiana, and Quercus alba. Contrib. from the Bot. Lab. Univ. Pennsyl., I9 6 , iv. 105-43.

6. CRIBBS, J. E.: Ecology of Tilia americana. I. Comparative Studies of Foliar Transpiring Power. Bot. Gaz., I9I9, lxviii. 262-86.

7. Darwin, F. : Observations on Stomata. Phil. Trans., B., I898, cxc. 548 .

8. 1 : A Self-recording Method applied to Movements of Stomata. Bot. Gaz., I904, xxxvii. 89 .

9. Proc. Roy. Soc., B., I9I I, lxxxiv. I 49.

10. Dixon, H. H.: Transpiration and the Ascent of Sap in Plants. Macmillan, I9I4.

11. FARmer, J. B.: On the Quantitative Differences in the Water Conductivity of Wood in Trees and Shrubs. Part II. Deciduous Plants. Proc. Royal Soc., B., I9I8, xc. 232-50.

12. Gray, J., and Peirce, G. J.: The Influence of Light upon the Action of Stomata and its Relation to the Transpiration of Certain Grains. Amer. Journ. Bot., I919, vi. I31-55.

13. Knight, R. C. : 'Relative Transpiration' as a Measure of the Intrinsic Transpiring Power of the Plant. Ann. Bot., I917, xxxi. 35I-59.

14. $:$ : On the Use of the Porometer in Stomatal Investigation. Ibid., I916, xxx. 57.

15. : Recent Work on Transpiration. New Phytol., I9I 7, xvi. I 29-39.

16. Laidlaw, C. G. P., and Knight, R. C. : A Description of a Recording Porometer and a Note on Stomatal Behaviour during Wilting. Ann. Bot., I9I6, xxx. 47-56.

17. Livingston, B. E., and Brown, W. H.: Relation of the Daily March of Transpiration to Variations in the Water Content of Foliage Leaves. Bot. Gaz., I9 I 2, liii. 309-30.

18. Neger, F. W.: Die Wegsamkeit der Laubblätter für Gase. Festschr. Z. E. Stahl., I9I 8, I 5 2-6 I.

19. Shreve, E. B.: Daily March of Transpiration in a Desert Perennial. Carn. Inst. Publ., 19I4, No. 20I. 


\section{$2 \mathrm{BHL}$ Biodiversity Heritage Library}

Knight, R. C. 1922. "Further observations on the transpiration, stomata, leaf water-content, and wilting of plants." Annals of botany 36, 361-383. https://doi.org/10.1093/oxfordjournals.aob.a089812.

View This Item Online: https://www.biodiversitylibrary.org/item/234428

DOI: https://doi.org/10.1093/oxfordjournals.aob.a089812

Permalink: https://www.biodiversitylibrary.org/partpdf/319049

\section{Holding Institution}

Smithsonian Libraries

\section{Sponsored by}

Biodiversity Heritage Library

\section{Copyright \& Reuse}

Copyright Status: Not in copyright. The BHL knows of no copyright restrictions on this item.

This document was created from content at the Biodiversity Heritage Library, the world's largest open access digital library for biodiversity literature and archives. Visit BHL at https://www.biodiversitylibrary.org. 